Published in final edited form as:

Lancet Haematol. 2015 May ; 2(5): e186-e193. doi:10.1016/S2352-3026(15)00048-4.

\title{
Prospective Analysis: Relative Survival in Patients with Chronic Myeloid Leukemia in Chronic Phase in the Era of Tyrosine Kinase Inhibitors
}

\author{
Koji Sasaki, MD',2, Sara S. Strom, PhD $^{3}$, Susan O'Brien, MD¹, Elias Jabbour, MD¹, Prof \\ Farhad Ravandi, MD1, Marina Konopleva, MD¹, Gautam Borthakur, MD¹, Naveen \\ Pemmaraju, MD1, Naval Daver, MD¹, Preetesh Jain, MD¹, Sherry Pierce, BSN ${ }^{1}$, Prof Hagop \\ Kantarjian, $\mathbf{M D}^{1}$, and Prof Jorge E. Cortes, MD ${ }^{1}$ \\ ${ }^{1}$ Department of Leukemia, The University of Texas MD Anderson Cancer Center, Houston, TX, \\ USA \\ ${ }^{2}$ Department of Hematology, Graduate School of Medical and Dental Sciences, Tokyo Medical \\ and Dental University, Tokyo, Japan \\ ${ }^{3}$ Department of Epidemiology, The University of Texas MD Anderson Cancer Center, Houston, \\ TX, USA
}

\section{Summary}

Background-Tyrosine kinase inhibitors (TKIs) improved overall survival (OS) in patients with chronic myeloid leukemia in chronic phase (CML-CP). The purpose of this study was to compare OS in patients with newly diagnosed CML-CP to that of general population.

\begin{abstract}
Methods-Response and survival data in six consecutive or parallel prospective clinical TKI trials were analyzed. Estimated OS rates in the general population matched by age, gender, ethnicity, and year at diagnosis were obtained from national vital statistics reports. Survival was also assessed by response and type of TKI.
\end{abstract}

Findings-Of the 483 patients, 271 patients received imatinib, 105 nilotinib and 107 dasatinib. The age grouping was as follows: 15-44 years, 197 patients; 45-64 years, 222; 65-84 years, 64.

\footnotetext{
This manuscript version is made available under the CC BY-NC-ND 4.0 license.

Corresponding Author: Jorge E. Cortes, MD, The University of Texas MD Anderson Cancer Center, 1515 Holcombe Blvd., Unit 428, Houston TX, 77030, USA, Phone: +1-713-794-5783, Fax: +1-713-794-4297, ; Email: jcortes@ mdanderson.org

Authorship contributions

K.S. collected data, designed the study, analyzed the data, and wrote the manuscript. J.C. treated the patients, designed the study, analyzed the data and edited the manuscript. S.S., designed the study and analyzed the data. S.P. managed the data. S.O., E.J., F.R., M.K., G.B., N,P., N.D., H.K. treated the patients. All authors provided significant intellectual input, and reviewed and approved the final version of the manuscript.

Conflicts of interests

E.J. received consultancy for Ariad, BMS, TEVA, and Pfizer. F.R. received research funding from Novartis and BMS. H.K. received research grants from Novaris, BMS, Pfizer, Ariad. J.C. received research support from Ariad, BMS, Novartis, Pfizer, and Teva, and is a consultant for Ariad, BMS, Novartis and Pfizer. Other authors have nothing to disclose.

Publisher's Disclaimer: This is a PDF file of an unedited manuscript that has been accepted for publication. As a service to our customers we are providing this early version of the manuscript. The manuscript will undergo copyediting, typesetting, and review of the resulting proof before it is published in its final citable form. Please note that during the production process errors may be discovered which could affect the content, and all legal disclaimers that apply to the journal pertain.
} 
Five-year OS in CML-CP decreased with increasing age: 15-44 years, 96\% (95\% confidence interval[CI], 93.2-99.2); 45-64 years, 94\% (95\%CI, 89.9-97.1); and 65-84 years, 80\% (95\%CI, 69.5-90.7). Five-year relative OS was only slightly lower compared to the matched general population: 15-44 years, 97\% (95\% CI, 94.0-100.0); 45-64 years, 97\% (95\%CI, 92.9-100.3); and 65-84 years, 92\% (95\%CI, 79.5-103.8). Five-year relative OS in all ages with complete cytogenetic response (CCyR) or better was similar to that in the general population.

Interpretation-With TKI, the expected survival of patients diagnosed with CML-CP is only slightly lower to that of the general population, and for those patients who achieved CCyR or better it is similar to that of general population. Due to the relatively smaller number of patients followed for 10 years and the small number of older patients, the 10-year relative OS has a wider confidence interval and might vary with longer follow-up. However, 10-year relative OS derived from the imatinib cohort is favorable, and, considering the overall better results with dasatinib and nilotinib, it is reasonable to expect that the results will remain at least as favorable with additional follow-up observation with dasatinib or nilotinib. Thus with access to TKI, it is possible that most patients with CML can enjoy a near normal life expectancy.

\section{Keywords}

Chronic myeloid leukemia; tyrosine kinase inhibitors; overall survival

\section{Introduction}

The prognosis of patients with chronic myeloid leukemia in chronic phase (CML-CP) has dramatically improved after the introduction of tyrosine kinase inhibitors (TKIs). ${ }^{1-5}$ The five-year overall survival (OS) with frontline imatinib was $89 \%$ at 60 months, and no patient who achieved complete cytogenetic response (CCyR) along with a major molecular response (MMR) at 12 months had progressed to the accelerated phase or blast phase at 60 months. ${ }^{6}$ In a recent analysis of the Surveillance, Epidemiology, and End Results (SEER) database, the five-year in the era of imatinib for patients age 15-44 years at the time of diagnosis was $86 \%$, compared to $76 \%$ for those age $45-64$ years, $51 \%$ for patients age $65-74$ and $36 \%$ for those age $75-84$ years. ${ }^{7}$

Relative survival describes the impact of a certain disease on survival compared to the survival reported for the overall population reported in population databases regardless of their health status (henceforth referred to as the "general population"). ${ }^{8}$ Relative survival is defined as the ratio of survival in a cohort of patients to the expected survival in the general population. In a recent analysis of the SEER data in the US and 11 cancer registries in Germany, the reported 5-year relative survival was $72.7 \%$ in the United States and $68.7 \%$ in Germany. ${ }^{9}$ These reports cover populations managed in a wide range of settings (e.g., academic and private practice, larger and smaller practices, specialized centers and general practices, etc.) but they do not allow an analysis of response to therapy and impact of specific variables in the outcomes obtained. In addition, the high medical cost of TKIs may limit access to these agents and affect outcomes. ${ }^{10}$

The purpose of this study was to compare OS in patients with newly diagnosed CML-CP treated with TKIs in a single, specialized institution, with full coverage of TKI through 
clinical trials, compared to that of general population using relative survival from matched general population estimated survival data.

\section{METHODS}

\section{Participants}

From May 2000 to January 2012, 483 consecutive patients with newly diagnosed CML-CP were enrolled in six consecutive or parallel prospective clinical trials at a single institution and were included in this analysis. Therapy consisted of imatinib (starting dose of $400 \mathrm{mg}$ or $800 \mathrm{mg}$ daily, alone or with pegylated interferon after six months of imatinib, dasatinib (50 $\mathrm{mg}$ orally twice daily or $100 \mathrm{mg}$ orally once daily), or nilotinib (400 $\mathrm{mg}$ orally twice daily). All the patients who enrolled in the clinical trials were included in this analysis. Demographic and clinical characteristics of all patients, response to therapy and survival data were analyzed. These trials were registered at www.clinicaltrials.gov as NCT00038649, NCT00048672, NCT00333840, NCT00050531, NCT00254423, and NCT00129740. All protocols were approved by the institutional review board and informed consent was obtained in accordance with the Declaration of Helsinki.

Diagnosis of CML in early chronic phase was defined as the presence of Philadelphia chromosome or BCR-ABL1 rearrangement with the presence in the peripheral blood of $<15 \%$ blasts, $<20 \%$ basophils, $<30 \%$ blasts and promyelocytes, and platelets $>100 \times 10^{9} / \mathrm{L}$, with a time interval from diagnosis to enrollment of 12 months or less. The inclusion criteria were similar for all trials, including age equal to or older than age 16, adequate heart, liver and renal function, and Eastern Cooperative Oncology Group (ECOG) performance status of 0-2. Patients with clonal evolution at the time of diagnosis were eligible for these studies.

The patients were divided into groups by age at diagnosis as follows: 15-44 years, 45-64 years, and 65-84 years. The age grouping matched previous publications with SEER database; the age 65-74 and age 75-84 groups were combined for the analysis due to the small number of patients. ${ }^{7}$ Response within 1 year start of therapy was analyzed using standard definitions ${ }^{11}$ : complete cytogenetic response (CCyR); major molecular response (MMR) (BCR-ABL1 transcript $₫) \cdot 1 \%$ on the international scale); MR4.5 (BCR-ABL1/ $A B L 1$ transcript $\$ 0.0032 \%$ in the international scale); or complete molecular response (CMR; undetectable transcripts with at least 100,000 ABL copies). OS was dated from the start of therapy until death from any cause at any time. Patients who were lost to follow-up were searched through the Social Security Death Index.

\section{Expected Survival in General Population}

Expected survival in general population was obtained from US national vital statistics data. ${ }^{12-22}$ Each patient with CML was matched to the survival data in general population databases adjusted by age, gender, race, and year of diagnosis. Survival probability for each matched person in the general population was calculated from the life table. Data from life tables in 2009 were used for matched control data in patients diagnosed in 2010 or later. Relative survival rates were calculated from the OS in the study population divided by the 
estimated OS in the general population. Relative OS rates were further analyzed by treatment and response.

\section{Statistical Method}

Chi-square test or Fisher exact test was used to compare categorical variables in patient characteristics. The probability of survival by age group was estimated by the Kaplan-Meier method. A log-rank test was used for univariate comparisons. $P$ values were two-tailed and $P$ values of less than 0.05 were considered statistically significant. A Cox proportional hazards model was used to identify prognostic factors with univariate and multivariate analysis for survival. Response data were analyzed as a separate time-dependent variable for the Cox hazards model. Statistical analysis was performed using Statistical Package for Social Sciences (SPSS) software (version 22, SPSS, Inc, Chicago, IL, USA). One-year landmark analysis was performed for confirmatory purpose. In 1-year landmark analysis, patients who died or were lost to follow-up within 1 year were excluded from the analysis.

\section{Role of the funding source}

The funding sources had no role in study design, data collection, data analysis, interpretation, or writing and revision of the manuscript. The corresponding author had full access to all the data reported in the manuscript.

\section{RESULTS}

\section{Study Population and Outcomes}

Among the 483 patients analyzed, 271 (56\%) were treated with imatinib including 70 (14\%) treated at a starting dose of $400 \mathrm{mg} /$ day, $43(9 \%)$ at $800 \mathrm{mg} /$ day, and $158(33 \%)$ with imatinib $800 \mathrm{mg} /$ day together with pegylated interferon (starting 6 months after the start of imatinib), 105 patients (21\%) were treated with nilotinib as frontline therapy, and 107 (22\%) with dasatinib. The median follow-up for the total study group was 99.4 months (interquartile range [IQR]; 45-122 months). Median follow-up was longer for patients treated with imatinib (126.3 months; IQR, 102-138 months), compared to those treated with nilotinib (47.8 months; IQR, 29-62 months) or dasatinib (50.4 months; IQR, 24-72 months). The age distribution of the 483 patients was as follows: 15-44 years, 197 patients (41\%); 45-64 years, 222 patients (46\%); and 65-84 years, 64 patients (13\%). No patients older than 85 years and no ethnic minority patients were enrolled in any of the trials.

The baseline characteristics are described in Table 1. Caucasian patients were significantly more common in age 65-84 group compared to other age groups $(p=0.028)$. The median follow-up, distribution by TKI therapy did not differ significantly between age groups. Similarly, the cumulative response rate to TKI within 1 year of start of treatment was comparable between age groups albeit with a trend for a worse response rate in the younger adults as previously reported. As expected, patients in age 65-84 had higher Sokal risk compared to those in age 15-44 and age 45-64 cohorts ( $\mathrm{p}<0 \cdot 0001)$. Five-year OS in age 6584 was $80 \%$ compared with $96 \%$ and $94 \%$ in age 15-44 and age 45-64 ( $p<0 \cdot 0001)$ (Figure 1). 


\section{Relative Survival}

The five-year and ten-year relative survival for the total cohort of patients with newly diagnosed CML-CP was $94.7 \%$ (95\% CI; 92.1-97.4) and 88.2\% (95\% CI; 83.7-92.9), respectively (Table 2). As each patient cohort was matched to equivalent general population groups based on age, gender, race, and calendar year at diagnosis, this resulted in slight difference in survival data from matched general population in each category. Five-year and ten-year relative survival was gradually lower with increasing age. Five-year and ten-year relative survival in the total cohort for patient that achieved best cumulative CCyR was 96.7\% (95\% CI; 94.2-99.1) and 92.1\% (95\% CI; 87.4-96.6), respectively. There was a trend for small improvement in relative survival with deeper cumulative response achieved within 1 year such that 10 -year relative survival was $88.2 \%$ for those irrespective response status, $92.1 \%$ for those patients with CCyR, 94.2\% for those achieving MMR, 94.0\% for patients with MR4.5, and $97.3 \%$ for patients with undetectable transcripts (Figure 2). This effect was noticeable across all age groups (Table 2). There is a trend of improvement in relative survival with deeper response within 1 year in the imatinib and nilotinib groups (Table 2-1). In the dasatinib group, the relative survival remained uniformly favorable irrespective of response (99.6\%; $95 \%$ CI $96.0 \%$ to $102 \%)$. Ten-year survival data in dasatinib or nilotinib cohorts were not available due to shorter follow-up. In all cohorts, patients who died during the follow-up after study drug discontinuation were included in the analysis.

\section{Cause of Death}

Overall, 53 deaths (11\%) were observed: 12 (6\%) among patients age 15-44 years, 19 (9\%) among those age 45-64 years, and 22 (34\%) among patients age 65-84 years. The causes of death by age group are shown in Table 3 and Supplemental Table $3-1$ to Table 3-3 by age group.

Of the 12 deaths in the age 15-44 group, eight patients had no CCyR within one year, two had CCyR, and two MR4.5. Among the eight patients without CCyR, three patients died of progression to CML-BP, two of stem cell transplant (SCT) complications after progression, two of unknown reasons and one patient on a car accident. Four of the eight patients without CCyR at one year could not receive dasatinib or nilotinib (not available at the time).

Of the 19 deaths in the age 45-64 group, seven patients had no CCyR within one year, five had CCyR, six had MMR and one had MR4.5. Three of the seven patients without CCyR at one year died of progression to CML-BP (two patients could not receive nilotinib or dasatinib - not available at the time-; one patient with clonal evolution at diagnosis received imatinib, dasatinib, bosutinib, ponatinib, and nilotinib), two died of complications of SCT (one for CML-CP after resistance to nilotinib, dasatinib and ponatinib and one for CML-BP after imatinib and dasatinib failure), one patient died in remission of renal cell carcinoma and one patient died of unknown reasons after discontinuation of imatinib due to lack of insurance. Among the five patients with CCyR, two died of progression to CML-BP (one patient could not receive dasatinib or nilotinib). Among the six patients with MMR, one died of metastatic breast cancer, and one of surgical complications after bowel obstructions, and one died of complications of SCT for CML-AP after developing imatinib resistance 
(dasatinib and nilotinib, not available). One patient in remission who achieved MR4.5 within one year died of acute myeloid leukemia (Philadelphia-chromosome negative).

Among the 22 deaths in the age 65-84 group, two patients had no CCyR within one year, eight had achieved CCyR, six had MMR, four MR4.5 and two had achieved CMR. Of the two patients that had not achieved CCyR, one with active CML-CP died of pneumonia and one died of progression to CML-BP. Of the eight patients who had achieved CCyR, one who had clonal evolution at diagnosis and achieved CCyR died of esophageal cancer with active CML-AP, one with active CML-AP died of unknown reasons (refused further therapy), one with active CML-CP (imatinib intolerance) died of a cardiovascular event, and three died in remission (from Parkinson's disease, metastatic melanoma, and surgical complications after femur fracture, respectively). All six patients that had achieved MMR died in remission including two patients with clonal evolution at diagnosis died of progressive dementia and cardiovascular event, respectively. The four patients that had achieved MR4.5 died in remission (from chronic lymphocytic leukemia, congestive heart failure, myocardial infarction, and unknown reasons, one each). The patient died of congestive heart failure had clonal evolution at diagnosis.

\section{Predictors of Survival}

We then performed univariate analysis and multivariate analysis to investigate factors associated with survival probability. Increasing age, presence of clonal evolution at the time of diagnosis, and lack of response were identified as poor prognostic factors for survival (Table 4). For multivariate analysis each response hallmark was used as a separate variable. Multivariate analysis for five-year survival demonstrated age at diagnosis, and lack of response as poor prognostic factors. The TKI used and Sokal risk score were not an independent factor for overall survival probability.

One-year Landmark Analysis-Results of one-year land mark analysis showed the similar findings seen in the overall analysis (Table 5; Table 6). In the landmark analysis, the relative survival was $88 \%$ for all patients, and $97 \%$ for those with CMR (Figure 2).

\section{DISCUSSION}

In this analysis we have shown that patients with CML treated with TKI have a relative survival similar to that of the general population, particularly if achieving a CCyR or better response by 1 year from the start of therapy. We have previously reported that the natural history of CML has significantly improved over the years based on data from a single institution, with the greatest impact occurring among patients diagnosed approximately after the year 2000 when TKI became a mainstay in the therapeutic arsenal of CML. ${ }^{23}$ Similarly, Surveillance, Epidemiology, and End Results (SEER) database analysis showed improved survival after introduction of multiple TKIs. ${ }^{7}$ With such improvement in overall survival, the question arises of whether the life expectancy of patients with CML treated with TKI may be reaching the life expectancy of individuals of their same age group in the general population. The analysis presented in this report aims to address this important question. Our analysis suggests that there is still a small but significant gap in relative survival for patients with CML. By five-years, the relative survival is nearly $95 \%$ that of the general population. 
However, by ten years, the gap widens with a relative survival of $88 \%$. Importantly, the tenyear relative survival rates reflect only treatment with imatinib as dasatinib and nilotinib were first introduced as frontline therapy in clinical trials in 2005. It remains to be seen whether the broader use of these agents may narrow the gap in relative survival by 10 years. The biggest difference in relative survival by overall response comes from the cohort of patients age 65 to 84 years at diagnosis, with 5- and 10-year relative survival rates of approximately $92 \%$ and $84 \%$. In contrast, younger patients have relative survival rates of 97\% and $92-94 \%$, respectively.

The survival of CML is greatly impacted by the response to therapy. It is well documented that achieving a CCyR significantly improves the life expectancy of patients, whether this is achieved with interferon therapy or with TKI. ${ }^{24-26}$ Indeed, patients achieving CCyR within one year from diagnosis have five- and ten-year relative survival rates of $96.7 \%$ and $92.1 \%$. The improvement is clearer in younger patients; those in age 65 to 84 years maintain a shorter relative survival both at five $(91.6 \%)$ and ten years $(83.6 \%)$. It has been debated whether deeper responses add survival value compared to achievement of CCyR. In our analysis, for the general cohort, there was only a modest trend for improved relative survival with deeper responses achieved within one year. For example, the 10 year relative survival improves from $92.1 \%$ for those achieving CCyR within 1 year, to $95.6 \%$ for those achieving undetectable transcript levels within the same time period. This improvement is noticeable within all age groups, including those age 65 to 84 years, whose relative survival is $91.4 \%$ if achieving only CCyR, but 100.3\% if achieving CMR. With the use of second generation TKIs as initial therapy deeper molecular responses occur earlier and in greater proportions. It is thus possible that the relative survival by ten years will improve as these agents are used more widely. Of note, relative survival greater than $100 \%$ was observed in patients with deep response. The finding, although statistically not significant, reflects in part some patient selection because of the eligibility criteria (e.g., good performance status, adequate organ function) to qualify for the studies as well as the close follow-up of these patients throughout their therapy.

To understand the gap in relative survival between patients with CML and the general population, we analyzed the causes of death for all patients. The most common cause of death was progression to advanced disease stage which was observed in 17 patients including five deaths due to SCT-related complications. Of note, ten patients did not receive second generation TKIs before progression as these were not widely available in the earlier years of the observation time for the study population. It is highly possible that a second-line TKI could have improved the outcome and possibly the survival for some patients after the front-line imatinib failure. The second common causes of deaths were cardiovascular events and secondary malignancies observed in 9 patients, respectively. There is increased awareness of the risk of cardiovascular events in patients treated with TKIs. ${ }^{27}$ Attention to this risk and mitigation strategies need to be addressed to minimize the risk of death from such events. Indeed, cardiovascular events consisted 32\% of death in age 65-84 compared to $8 \%$ and $5 \%$ in age $15-44$ and age $45-64$, respectively.

Second malignancies seen in this study include two patients with esophageal cancer, one with renal cell carcinoma, one with melanoma, one with breast cancer, one with ovarian 
cancer, one with acute myeloid leukemia, one with chronic lymphocytic leukemia. Whether use of TKIs increase the risk of developing other malignancies is controversial. Verma et al. reported secondary malignancies during TKI therapy in $4.6 \% .^{28}$ In this analysis, the incidence was not different than the expected in the general population. However, other studies have suggested there might be a higher incidence of second malignancies associated with TKI therapy. ${ }^{29}$ Data about the estimated cause of death in the general population used for this analysis is not available to the same detail as we have in the study population. With such registry data it is not possible to match patients further to ensure comparability for the causes of death considering risk factors and individual demographic information. In addition, it is challenging to find a correlation of specific type of TKI to each type of secondary malignancy or risk of cardiovascular events because of the overall small number of deaths.

In our analysis, the type of TKI used did not influence the survival probabilities. In addition, Cox proportional hazards analysis with a time dependent variable showed that achieving MMR within 1 year from the start of treatment had the highest hazard ratio, with a tendency for smaller hazard ratios with deeper responses. Of note, none of patients who achieved MR4.5 or better did die directly from CML with the median follow-up of 99 months.

There are several limitations in our study. First, this is a single institution cohort of patients enrolled in consecutive prospective clinical trials and the disease assessment and follow-up timing were performed as per protocol. Thus, it is possible that the results are not representative of the general US population. However, we have reported that outcome of patients treated within or outside clinical trials at our institution is equivalent, and that patients characteristics such as median income, education and insurance coverage are similar to those of the general population of the US. ${ }^{30}$ We have previously reported that patient education and social status was similar for patients treated with imatinib on protocol (population included in this analysis) or off protocol (not included in this analysis), and comparable to those in the general population of the US. Although it is likely that the same findings would be observed for the nilotinib and dasatinib groups, this information was not available for comparison. Second, patients with significant co-morbidities including heart failure, chronic kidney disease, liver cirrhosis, other active cancers were excluded from clinical trials and thus are not included in this analysis. Patients with common medical diseases such as hypertension, diabetes mellitus, hyperlipidemia, history of myocardial infarction, distant history of cancer could enroll in our study. Third, no patient over age 85 was enrolled in this study and patients at age 65-84 have relatively few. Also, although we have previously reported that patients enrolled on clinical trials of imatinib in our institution appear to be representative of the general population of the United States, information of variables such education status, income, and health insurance coverage was not collected for this analysis. Thus, it is possible that other cohorts have an imbalance in these features or in the proportional representation of minorities. Further studies are needed to clarify the survival benefit in elderly population and ethnic minority patients with CML-CP and the development of less toxic TKI is mandatory for long term use in this population. Finally, our study group had a relatively low incidence of patients with high-risk Sokal score. There is wide variability in the percentage of high-risk Sokal patients in the few population studies that have been reported from approximately $20 \%$ to $33 \% .{ }^{31-33}$ Although it has been 
suggested that in the US the percentage of patients who present with high-risk Sokal scores is lower, no population studies have been published from the US to confirm this. In fact two recent registries have shown that unfortunately Sokal risk is only being calculated in 10$30 \%$ of patients, making broad characterization of patient scores difficult. ${ }^{34-35}$

In conclusion, with TKI therapy the OS rates in patients with newly diagnosed CML-CP are only slightly lower to that of general population. However, the OS rates in patients who achieved CCyR or better are similar to that of general population. This emphasizes the need for optimal management of patients with CML at all ages to offer the full benefit provided by these life-transforming therapies.

\section{Supplementary Material}

Refer to Web version on PubMed Central for supplementary material.

\section{Acknowledgments}

This study was supported in part by the MD Anderson Cancer Center Support Grant CA016672 and Award Number P01 CA049639 from the National Cancer Institute. The authors thank Dr. O. Miura (Tokyo Medical and Dental University) for helpful advice.

\section{References}

1. Kantarjian HM, Talpaz M, O'Brien S, et al. Survival benefit with imatinib mesylate versus interferon-alpha-based regimens in newly diagnosed chronic-phase chronic myelogenous leukemia. Blood. 2006; 108(6):1835-40. [PubMed: 16709931]

2. Hochhaus A, Saglio G, Larson RA, et al. Nilotinib is associated with a reduced incidence of BCRABL mutations vs imatinib in patients with newly diagnosed chronic myeloid leukemia in chronic phase. Blood. 2013; 121(18):3703-8. [PubMed: 23502220]

3. Kantarjian HM, Shah NP, Cortes JE, et al. Dasatinib or imatinib in newly diagnosed chronic-phase chronic myeloid leukemia: 2-year follow-up from a randomized phase 3 trial (DASISION). Blood. 2012; 119(5):1123-9. [PubMed: 22160483]

4. Cortes JE, Kim DW, Kantarjian HM, et al. Bosutinib versus imatinib in newly diagnosed chronicphase chronic myeloid leukemia: results from the BELA trial. Journal of clinical oncology : official journal of the American Society of Clinical Oncology. 2012; 30(28):3486-92. [PubMed: 22949154]

5. Cortes JE, Kantarjian H, Shah NP, et al. Ponatinib in refractory Philadelphia chromosome-positive leukemias. The New England journal of medicine. 2012; 367(22):2075-88. [PubMed: 23190221]

6. Druker BJ, Guilhot F, O'Brien SG, et al. Five-year follow-up of patients receiving imatinib for chronic myeloid leukemia. The New England journal of medicine. 2006; 355(23):2408-17. [PubMed: 17151364]

7. Brunner AM, Campigotto F, Sadrzadeh H, et al. Trends in all-cause mortality among patients with chronic myeloid leukemia: a Surveillance, Epidemiology, and End Results database analysis. Cancer. 2013; 119(14):2620-9. [PubMed: 23625575]

8. Ederer F, Axtell LM, Cutler SJ. The relative survival rate: a statistical methodology. National Cancer Institute monograph. 1961; 6:101-21. [PubMed: 13889176]

9. Pulte D, Barnes B, Jansen L, et al. Population level survival of patients with chronic myelocytic leukemia in Germany compared to the US in the early 21 st century. Journal of hematology \& oncology. 2013; 6(1):70. [PubMed: 24499592]

10. Dusetzina SB, Winn AN, Abel GA, Huskamp HA, Keating NL. Cost sharing and adherence to tyrosine kinase inhibitors for patients with chronic myeloid leukemia. Journal of clinical oncology : official journal of the American Society of Clinical Oncology. 2014; 32(4):306-11. [PubMed: 24366936] 
11. Baccarani M, Deininger MW, Rosti G, et al. European LeukemiaNet recommendations for the management of chronic myeloid leukemia: 2013. Blood. 2013; 122(6):872-84. [PubMed: 23803709]

12. Arias E. United States life tables, 2000. National vital statistics reports : from the Centers for Disease Control and Prevention, National Center for Health Statistics, National Vital Statistics System. 2002; 51(3):1-38.

13. Arias E. United States Life Tables, 2001. National vital statistics reports : from the Centers for Disease Control and Prevention, National Center for Health Statistics, National Vital Statistics System. 2004; 52(14):1-38.

14. Arias E. United States life tables, 2002. National vital statistics reports : from the Centers for Disease Control and Prevention, National Center for Health Statistics, National Vital Statistics System. 2004; 53(6):1-38.

15. Arias E. United States life tables, 2003. National vital statistics reports : from the Centers for Disease Control and Prevention, National Center for Health Statistics, National Vital Statistics System. 2006; 54(14):1-40.

16. Arias E. United States life tables, 2004. National vital statistics reports : from the Centers for Disease Control and Prevention, National Center for Health Statistics, National Vital Statistics System. 2007; 56(9):1-39.

17. Arias E, Rostron BL, Tejada-Vera B. United States life tables, 2005. National vital statistics reports : from the Centers for Disease Control and Prevention, National Center for Health Statistics, National Vital Statistics System. 2010; 58(10):1-132.

18. Arias E. United States life tables, 2006. National vital statistics reports : from the Centers for Disease Control and Prevention, National Center for Health Statistics, National Vital Statistics System. 2010; 58(21):1-40.

19. Arias E. United States life tables, 2007. National vital statistics reports : from the Centers for Disease Control and Prevention, National Center for Health Statistics, National Vital Statistics System. 2011; 59(9):1-60.

20. Arias E. United States life tables, 2008. National vital statistics reports : from the Centers for Disease Control and Prevention, National Center for Health Statistics, National Vital Statistics System. 2012; 61(3):1-63.

21. Arias E. United States life tables, 2009. National vital statistics reports : from the Centers for Disease Control and Prevention, National Center for Health Statistics, National Vital Statistics System. 2014; 62(7):1-63.

22. Zagars GK, Ballo MT, Lee AK, Strom SS. Mortality after cure of testicular seminoma. Journal of clinical oncology : official journal of the American Society of Clinical Oncology. 2004; 22(4): 640-7. [PubMed: 14726503]

23. Kantarjian H, O'Brien S, Jabbour E, et al. Improved survival in chronic myeloid leukemia since the introduction of imatinib therapy: a single-institution historical experience. Blood. 2012; 119(9): 1981-7. [PubMed: 22228624]

24. Kantarjian HM, O'Brien S, Cortes JE, et al. Complete cytogenetic and molecular responses to interferon-alpha-based therapy for chronic myelogenous leukemia are associated with excellent long-term prognosis. Cancer. 2003; 97(4):1033-41. [PubMed: 12569603]

25. Kantarjian HM, Shan J, Jones D, et al. Significance of increasing levels of minimal residual disease in patients with Philadelphia chromosome-positive chronic myelogenous leukemia in complete cytogenetic response. Journal of clinical oncology : official journal of the American Society of Clinical Oncology. 2009; 27(22):3659-63. [PubMed: 19487383]

26. Jabbour E, Kantarjian H, O'Brien S, et al. Predictive factors for outcome and response in patients treated with second-generation tyrosine kinase inhibitors for chronic myeloid leukemia in chronic phase after imatinib failure. Blood. 2011; 117(6):1822-7. [PubMed: 21030554]

27. Jabbour E, Deininger M, Hochhaus A. Management of adverse events associated with tyrosine kinase inhibitors in the treatment of chronic myeloid leukemia. Leukemia. 2011; 25(2):201-10. [PubMed: 20861918] 
28. Verma D, Kantarjian H, Strom SS, et al. Malignancies occurring during therapy with tyrosine kinase inhibitors (TKIs) for chronic myeloid leukemia (CML) and other hematologic malignancies. Blood. 2011; 118(16):4353-8. [PubMed: 21846902]

29. Roy L, Guilhot J, Martineau G, Larchee R, Guilhot F. Unexpected occurrence of second malignancies in patients treated with interferon followed by imatinib mesylate for chronic myelogenous leukemia. Leukemia. 2005; 19(9):1689-92. [PubMed: 16015386]

30. Yilmaz M, Kantarjian H, Jabbour E, et al. Similar outcome of patients with chronic myeloid leukemia treated with imatinib in or out of clinical trials. Clinical lymphoma, myeloma \& leukemia. 2013; 13(6):693-9.

31. Corm, Selim; Roche, Laurent; Micol, Jean-Baptiste, et al. Changes in the dynamics of the excess mortality rate in chronic phase-chronic myeloid leukemia over 1990-2007: a population study. Blood. 2011; 118(16):4331-7. [PubMed: 21849485]

32. Höglund, Martin; Sandin, Fredrik; Hellström, Karin, et al. Tyrosine kinase inhibitor usage, treatment outcome, and prognostic scores in CML: report from the population-based Swedish CML registry. Blood. 2013; 122(7):1284-92. [PubMed: 23843494]

33. Faber, Edgar; Mužík, Jan; Koza, Vladimír, et al. Treatment of consecutive patients with chronic myeloid leukaemia in the cooperating centres from the Czech Republic and the whole of Slovakia after 2000-a report from the population-based CAMELIA Registry. Eur J Haematol. 2011; 87(2): 157-68. [PubMed: 21535160]

34. Cortes, Jorge E.; Hehlmann, Rüdiger; Gambacorti-Passerini, Carlo, et al. Baseline characteristics of patients with chronic myeloid leukemia in a prospective observational study (SIMPLICITY). Blood. 2013; 122(21):4026.

35. Robert, Hermann; Miller, Carole B.; Catchatorian, Rosalind, et al. Understanding United States treatment practices for the management of chronic myeloid leukemia in clinical practice: A US subgroup analysis of the WORLD CML registry. Blood. 2012; 120(21):2781. [PubMed: 23043027]

\section{Appendix}

Table 2-1

Relative survival by tyrosine kinase inhibitor and cumulative response within 1 year

\begin{tabular}{|c|c|c|c|c|c|c|c|c|}
\hline Group & $\begin{array}{l}\text { No. } \\
\text { at } 5 y\end{array}$ & $\begin{array}{c}\text { 5-y Absolute } \\
\text { OS } \\
{[95 \% \mathrm{CI}]}\end{array}$ & $\begin{array}{c}\text { 5-y Relative OS } \\
{[95 \% \text { CI] }}\end{array}$ & $\begin{array}{l}5 \text {-y OS } \\
\text { in GP }\end{array}$ & $\begin{array}{l}\text { No. } \\
\text { at } 10 y\end{array}$ & $\begin{array}{c}\text { 10-y Absolute } \\
\text { OS } \\
{[95 \% \text { CI] }}\end{array}$ & $\begin{array}{c}\text { 10-y Relative OS } \\
{[95 \% \text { CI }]}\end{array}$ & $\begin{array}{l}\text { 10-y OS } \\
\text { in GP }\end{array}$ \\
\hline \multicolumn{9}{|l|}{ All TKI Group } \\
\hline All $N=483$ & 312 & $92 \cdot 7[90 \cdot 1-95 \cdot 3]$ & $94 \cdot 8[92 \cdot 1-97 \cdot 4]$ & $97 \cdot 8$ & 127 & $83 \cdot 5[79 \cdot 2-87 \cdot 9]$ & $88 \cdot 3[83.7-92.9]$ & $94 \cdot 6$ \\
\hline CCyR N=425 & 284 & $94 \cdot 5$ [92.1-96.9] & $96 \cdot 6[94 \cdot 2-99 \cdot 1]$ & $97 \cdot 8$ & 115 & $87 \cdot 1[82 \cdot 7-91 \cdot 4]$ & $92 \cdot 1[87 \cdot 4-96 \cdot 6]$ & $94 \cdot 6$ \\
\hline MMR N=349 & 234 & $96.5[94 \cdot 4-98 \cdot 7]$ & $98.7[96 \cdot 5-100 \cdot 9]$ & $97 \cdot 8$ & 91 & $89 \cdot 0[84 \cdot 5-93 \cdot 7]$ & $94 \cdot 1[89 \cdot 3-99 \cdot 0]$ & $94 \cdot 6$ \\
\hline MR4.5 N=162 & 105 & $95 \cdot 8[92 \cdot 1-99 \cdot 4]$ & $98 \cdot 1[94 \cdot 3-101 \cdot 7]$ & $97 \cdot 7$ & 47 & $88.5[81.9-95 \cdot 0]$ & $93.9[86 \cdot 9-100 \cdot 8]$ & $94 \cdot 2$ \\
\hline CMR N=84 & 53 & $98 \cdot 6[95 \cdot 8-100]$ & $100 \cdot 9[98 \cdot 1-102 \cdot 4]$ & $97 \cdot 7$ & 21 & $91 \cdot 7[82 \cdot 2-100]$ & $97 \cdot 3[87 \cdot 3-106 \cdot 2]$ & $94 \cdot 2$ \\
\hline \multicolumn{9}{|l|}{ Imatinib Group } \\
\hline All N=271 & 239 & $92 \cdot 4[89 \cdot 2-95 \cdot 6]$ & $94.5[91.2-97.8]$ & $97 \cdot 8$ & 127 & $83 \cdot 3[78 \cdot 5-88 \cdot 0]$ & 88.0 [82.9-92.9] & $94 \cdot 7$ \\
\hline CCyR N=229 & 212 & $94 \cdot 7[91 \cdot 8-97 \cdot 6]$ & $96.9[94 \cdot 0-99 \cdot 9]$ & $97 \cdot 7$ & 115 & $87.4[82.8-92.0]$ & $92 \cdot 8[87 \cdot 9-97 \cdot 7]$ & $94 \cdot 2$ \\
\hline MMR N=184 & 176 & $97 \cdot 3$ [94.9-99.6] & $99.5[97 \cdot 0-101.8]$ & $97 \cdot 8$ & 91 & $90 \cdot 0[85 \cdot 2-94 \cdot 8]$ & $95 \cdot 1[90 \cdot 1-100 \cdot 2]$ & $94 \cdot 6$ \\
\hline MR4 5 N=81 & 78 & $97.5[94 \cdot 1-100]$ & $100 \cdot 1[96 \cdot 6-102 \cdot 7]$ & $97 \cdot 4$ & 47 & $89 \cdot 7$ [82.9-96.5] & $95.6[88.4-102.9]$ & $93 \cdot 8$ \\
\hline $\mathrm{CMR} N=34$ & 33 & 100 & $102 \cdot 5$ & $97 \cdot 6$ & 21 & $93 \cdot 1[83 \cdot 7-100]$ & $99 \cdot 0[89 \cdot 0-106 \cdot 4]$ & $94 \cdot 0$ \\
\hline \multicolumn{9}{|l|}{ Dasatinib Group } \\
\hline All N=107 & 40 & $97 \cdot 6[94 \cdot 1-100]$ & $99 \cdot 6[96 \cdot 0-102]$ & $98 \cdot 0$ & 0 & NA & NA & $95 \cdot 1$ \\
\hline
\end{tabular}




\begin{tabular}{|c|c|c|c|c|c|c|c|c|}
\hline Group & $\begin{array}{l}\text { No. } \\
\text { at } 5 y\end{array}$ & $\begin{array}{c}\text { 5-y Absolute } \\
\text { OS } \\
{[95 \% \text { CI] }}\end{array}$ & $\begin{array}{c}\text { 5-y Relative OS } \\
{[95 \% \text { CI }]}\end{array}$ & $\begin{array}{l}\text { 5-y OS } \\
\text { in GP }\end{array}$ & $\begin{array}{l}\text { No. } \\
\text { at } 10 y\end{array}$ & $\begin{array}{c}\text { 10-y Absolute } \\
\text { OS } \\
{[95 \% \mathrm{CI}]}\end{array}$ & $\begin{array}{c}\text { 10-y Relative OS } \\
{[95 \% \text { CI }]}\end{array}$ & $\begin{array}{l}\text { 10-y OS } \\
\text { in GP }\end{array}$ \\
\hline CCyR N=99 & 39 & $97 \cdot 4$ [93.7-100] & $99 \cdot 6[95 \cdot 8-102 \cdot 2]$ & $97 \cdot 8$ & 0 & NA & NA & $94 \cdot 7$ \\
\hline MMR N=79 & 30 & $98 \cdot 7[96 \cdot 1-100]$ & $100 \cdot 9[98 \cdot 3-102 \cdot 2]$ & $97 \cdot 8$ & 0 & NA & NA & $94 \cdot 7$ \\
\hline MR4.5 N=38 & 12 & 100 & $102 \cdot 1$ & 97.9 & 0 & NA & NA & 94.9 \\
\hline CMR N=27 & 9 & 100 & $102 \cdot 2$ & $97 \cdot 8$ & 0 & NA & NA & 94.7 \\
\hline \multicolumn{9}{|l|}{ Nilotinib Group } \\
\hline All N=105 & 33 & $87 \cdot 6[78 \cdot 5-96 \cdot 7]$ & $89 \cdot 6$ [80.3-98.9] & $97 \cdot 8$ & 0 & NA & NA & $94 \cdot 6$ \\
\hline CCyR N=97 & 33 & $89 \cdot 8$ [81.0-98.6] & $91 \cdot 9$ [82.9-100.9] & $97 \cdot 7$ & 0 & NA & NA & $94 \cdot 3$ \\
\hline MMR N=86 & 28 & $90 \cdot 9$ [82.0-99.9] & $93 \cdot 0[83 \cdot 9-102 \cdot 2]$ & $97 \cdot 7$ & 0 & NA & NA & $94 \cdot 4$ \\
\hline MR $4.5 \mathrm{~N}=43$ & 15 & $85 \cdot 6[70 \cdot 2-100]$ & $87 \cdot 7$ [71.9-102.5] & $97 \cdot 6$ & 0 & NA & NA & $94 \cdot 1$ \\
\hline CMR N=23 & 11 & $94 \cdot 1$ [82.9-100] & $96 \cdot 4[84 \cdot 9-102 \cdot 5]$ & $97 \cdot 6$ & 0 & NA & NA & $94 \cdot 2$ \\
\hline
\end{tabular}

Abbreviations: OS, overall survival; GP, general population; CI, confidence interval; CCyR, complete cytogenetic response; MMR, major molecular response; MR4.5, molecular response with 4.5 log reduction by international scale; CMR, complete molecular response; NA, not applicable.

\section{Table 3-1}

Cause of death by cumulative response within 1 year in age 15-44

\begin{tabular}{|c|c|c|c|c|c|}
\hline Age 15-44 & All N= 197 & $\operatorname{CCyR}^{*} N=165$ & $M R^{*} N=136$ & MR4.5* $N=62$ & CMR N=34 \\
\hline Number of death, $(\%)$ & $12(6)$ & $4(2)$ & $3(2)$ & $1(1)$ & 0 \\
\hline Progression to AP/BP, $(\%)$ & $5(42)$ & 0 & 0 & 0 & 0 \\
\hline SCT complications, $(\%)$ & $3(25)$ & $1(25)$ & $1(33)$ & 0 & 0 \\
\hline Cardiovascular events, $(\%)$ & $1(8)$ & $1(25)$ & 0 & 0 & 0 \\
\hline Car accident, No. (\%) & $2(17)$ & $1(25)$ & $1(33)$ & 0 & 0 \\
\hline Other, No. (\%) & $1(8)$ & $1(25)$ & $1(33)$ & $1(100)$ & 0 \\
\hline \multicolumn{6}{|l|}{ Type of TKI, No. (\%) } \\
\hline Imatinib & $12(100)$ & $4(100)$ & $3(100)$ & $1(100)$ & 0 \\
\hline Dasatinib & 0 & 0 & 0 & 0 & 0 \\
\hline Nilotinib & 0 & 0 & 0 & 0 & 0 \\
\hline \multicolumn{6}{|c|}{ Overall cumulative response, No. (\%) } \\
\hline CCyR & $4(33)$ & $4(100)$ & $3(100)$ & $1(100)$ & 0 \\
\hline MMR & $3(25)$ & $3(75)$ & $3(100)$ & $1(100)$ & 0 \\
\hline MR4.5 & $2(17)$ & $2(50)$ & $2(67)$ & $1(100)$ & 0 \\
\hline CMR & $1(8)$ & $1(25)$ & $1(33)$ & $1(100)$ & 0 \\
\hline \multicolumn{6}{|c|}{ Disease status $^{* *}$ at the time of death, No. $(\%)$} \\
\hline CML-AP/BP & $3(25)$ & 0 & 0 & 0 & 0 \\
\hline $\mathrm{CHR}$ & $1(8)$ & 0 & 0 & 0 & 0 \\
\hline CCyR & $1(8)$ & 0 & 0 & 0 & 0 \\
\hline MMR & $1(8)$ & $1(25)$ & $1(33)$ & 0 & 0 \\
\hline MR4.5 & $1(8)$ & $1(25)$ & $1(33)$ & $1(100)$ & 0 \\
\hline CMR & $3(25)$ & $2(50)$ & $1(33)$ & 0 & 0 \\
\hline
\end{tabular}




\begin{tabular}{|c|c|c|c|c|c|}
\hline Age 15-44 & All N= 197 & CCyR $^{*} \mathbf{N}=\mathbf{1 6 5}$ & MMR $^{*} \mathbf{N}=136$ & MR4·5 $^{*}$ N=62 & CMR N=34 \\
\hline Unknown & $2(17)$ & 0 & 0 & 0 & 0 \\
\hline
\end{tabular}

*CyR includes CCyR or better; MMR includes MMR or better; MR4.5 includes MR4.5 or better.

Each status represents the best category of response or disease status at the time of death.

Abbreviations: AP, accelerated phase; BP, blast phase; $\mathrm{CP}$, chronic phase; $\mathrm{CCyR}$, complete cytogenetic response; MMR, major molecular response; MR4.5, molecular response by a $4.5 \log$ reduction on the international scale; CMR, complete molecular response; SCT, stem cell transplant; TKI, tyrosine kinase inhibitor; CML, chronic myeloid leukemia.

\section{Table 3-2}

Cause of death by cumulative response within 1 year in age 45-64

\begin{tabular}{|c|c|c|c|c|c|}
\hline Age 45-64 & All $\mathbf{N}=\mathbf{2 2 2}$ & $\operatorname{CCyR}^{*} N=202$ & $\mathrm{MMR}^{*} \mathrm{~N}=169$ & MR4.5* $N=75$ & CMR N=40 \\
\hline Number of death, No. (\%) & $19(9)$ & $12(6)$ & $7(4)$ & $3(2)$ & 0 \\
\hline $\begin{array}{l}\text { Progression to AP/BP, No. } \\
(\%)\end{array}$ & $5(26)$ & $3(25)$ & $1(14)$ & 0 & 0 \\
\hline SCT complications, No. $(\%)$ & $2(11)$ & 0 & 0 & 0 & 0 \\
\hline $\begin{array}{l}\text { Secondary malignancy, No. } \\
(\%)\end{array}$ & $4(21)$ & $3(25)$ & $2(29)$ & $1(33)$ & 0 \\
\hline $\begin{array}{l}\text { Cardiovascular events, No. } \\
(\%)\end{array}$ & $1(5)$ & $1(8)$ & $1(14)$ & 0 & 0 \\
\hline Sepsis, No. (\%) & $1(5)$ & $1(8)$ & 0 & 0 & 0 \\
\hline Dementia, No. (\%) & $1(5)$ & $1(8)$ & $1(14)$ & $1(33)$ & 0 \\
\hline $\begin{array}{l}\text { Surgical complications, No. } \\
(\%)\end{array}$ & $1(5)$ & $1(8)$ & $1(14)$ & 0 & 0 \\
\hline HCV cirrhosis, No. (\%) & $1(5)$ & 0 & 0 & 0 & 0 \\
\hline Unknown, No. (\%) & $3(16)$ & $2(17)$ & $1(14)$ & $1(33)$ & 0 \\
\hline \multicolumn{6}{|l|}{ Type of TKI, No. (\%) } \\
\hline Imatinib & $15(79)$ & $10(83)$ & $6(86)$ & $3(100)$ & 0 \\
\hline Dasatinib & $1(5)$ & $1(8)$ & $1(14)$ & 0 & 0 \\
\hline Nilotinib & $3(16)$ & $1(8)$ & 0 & 0 & 0 \\
\hline \multicolumn{6}{|c|}{ Overall cumulative response, No. $(\%)$} \\
\hline CCyR & $14(74)$ & $12(100)$ & $7(100)$ & $3(100)$ & 0 \\
\hline MMR & $11(58)$ & $9(75)$ & $7(100)$ & $3(100)$ & 0 \\
\hline MR4.5 & $5(26)$ & $4(33)$ & $3(43)$ & $3(100)$ & 0 \\
\hline CMR & $3(16)$ & $2(17)$ & $1(14)$ & $1(33)$ & 0 \\
\hline \multicolumn{6}{|c|}{ Disease status ${ }^{* *}$ at the time of death, No. (\%) } \\
\hline CML-AP/BP & $5(26)$ & $3(25)$ & $1(14)$ & 0 & 0 \\
\hline CML-CP & $1(5)$ & $1(8)$ & 0 & 0 & 0 \\
\hline CCyR & $1(5)$ & $1(8)$ & $1(14)$ & 0 & 0 \\
\hline MMR & $3(16)$ & $3(25)$ & $2(29)$ & 0 & 0 \\
\hline MR4.5 & $2(11)$ & $2(17)$ & $2(29)$ & $2(67)$ & 0 \\
\hline CMR & $5(26)$ & $1(8)$ & 0 & 0 & 0 \\
\hline Unknown & $2(11)$ & $1(8)$ & $1(14)$ & $1(33)$ & 0 \\
\hline
\end{tabular}

CCyR includes CCyR or better; MMR includes MMR or better; MR4.5 includes MR4.5 or better. 
Each status represents the best category of response or disease status at the time of death.

Abbreviations: AP, accelerated phase; BP, blast phase; CP, chronic phase; CCyR, complete cytogenetic response; MMR, major molecular response; MR4.5, molecular response by a $4.5 \log$ reduction on the international scale; CMR, complete molecular response; SCT, stem cell transplant; TKI, tyrosine kinase inhibitor; CML, chronic myeloid leukemia; HCV, hepatitis $\mathrm{C}$ virus.

\section{Table 3-3}

Cause of death by cumulative response within 1 year in age 65-84

\begin{tabular}{|c|c|c|c|c|c|}
\hline Age 65-84 & All N= 64 & $\operatorname{CCyR}^{*} \mathrm{~N}=58$ & $\operatorname{MMR}^{*} \mathrm{~N}=44$ & $\operatorname{MR4} \cdot 5^{*} \mathrm{~N}=25$ & CMR N=11 \\
\hline Number of death, No. (\%) & $22(34)$ & $20(34)$ & $13(25)$ & $8(17)$ & $3(9)$ \\
\hline Progression to AP/BP, No. (\%) & $2(9)$ & $1(5)$ & 0 & 0 & 0 \\
\hline Secondary malignancy, No. (\%) & $5(23)$ & $5(25)$ & $3(23)$ & $2(25)$ & $1(33)$ \\
\hline Cardiovascular events, No. (\%) & $7(32)$ & $7(35)$ & $4(31)$ & $3(6)$ & 0 \\
\hline Sepsis, No. (\%) & $1(5)$ & $1(5)$ & $1(8)$ & $1(13)$ & $1(33)$ \\
\hline Dementia, No. (\%) & $1(5)$ & $1(5)$ & $1(8)$ & 0 & 0 \\
\hline Surgical complications, No. (\%) & $1(5)$ & $1(5)$ & $1(8)$ & 0 & 0 \\
\hline Bowel obstruction, No. (\%) & $1(5)$ & 0 & 0 & 0 & 0 \\
\hline $\begin{array}{l}\text { Gastrointestinal bleeding, No. } \\
(\%)\end{array}$ & $1(5)$ & $1(5)$ & 0 & 0 & 0 \\
\hline Parkinson disease, No. (\%) & $1(5)$ & $1(5)$ & $1(8)$ & 0 & 0 \\
\hline Unknown, No. (\%) & $2(9)$ & $2(10)$ & $2(15)$ & $2(25)$ & $1(33)$ \\
\hline \multicolumn{6}{|l|}{ Type of TKI, No. (\%) } \\
\hline Imatinib & $16(73)$ & $14(70)$ & $8(62)$ & $5(63)$ & $2(67)$ \\
\hline Dasatinib & $2(9)$ & $2(10)$ & $1(8)$ & 0 & 0 \\
\hline Nilotinib & $4(18)$ & $4(20)$ & $4(31)$ & $3(38)$ & $1(33)$ \\
\hline \multicolumn{6}{|l|}{ Overall cumulative response, No. (\%) } \\
\hline CCyR & $20(91)$ & $20(100)$ & $13(100)$ & $8(100)$ & $3(100)$ \\
\hline MMR & $14(64)$ & $14(70)$ & $13(100)$ & $8(100)$ & $3(100)$ \\
\hline MR4.5 & $12(55)$ & $12(60)$ & $11(85)$ & $8(100)$ & $3(100)$ \\
\hline CMR & $8(36)$ & $8(40)$ & $7(54)$ & $5(63)$ & $3(100)$ \\
\hline \multicolumn{6}{|c|}{ Disease status $^{* *}$ at the time of death, No. $(\%)$} \\
\hline CML-AP/BP & $1(5)$ & 0 & 0 & 0 & 0 \\
\hline CML-CP & $2(9)$ & $2(10)$ & 0 & 0 & 0 \\
\hline CHR & $2(9)$ & $1(5)$ & 0 & 0 & 0 \\
\hline CCyR & $1(5)$ & $1(5)$ & 0 & 0 & 0 \\
\hline MMR & $3(14)$ & $3(15)$ & $2(15)$ & $1(13)$ & $1(33)$ \\
\hline MR4.5 & $4(18)$ & $4(20)$ & $4(31)$ & $3(38)$ & 0 \\
\hline CMR & $5(23)$ & $5(25)$ & $4(31)$ & $2(25)$ & $1(33)$ \\
\hline Unknown & $3(14)$ & $4(20)$ & $3(23)$ & $2(25)$ & $1(33)$ \\
\hline
\end{tabular}

Abbreviations: AP, accelerated phase; BP, blast phase; $\mathrm{CP}$, chronic phase; CCyR, complete cytogenetic response; MMR, major molecular response; MR4.5, molecular response by a $4.5 \log$ reduction on the international scale; CMR, complete molecular response; SCT, stem cell transplant; TKI, tyrosine kinase inhibitor; CML, chronic myeloid leukemia. 
Table 4

Multivariate Cox proportional hazards analysis of overall survival

\begin{tabular}{|l|c|c|c|c|}
\hline \multirow{2}{*}{ Variable } & Univariate & \multicolumn{3}{|c|}{ Multivariate Analysis } \\
\cline { 2 - 5 } & $\boldsymbol{P}$ & $\boldsymbol{P}$ & HR & 95\% CI \\
\hline Age at diagnosis & $<0.0001$ & $<0.0001$ & 1.045 & $1.026-1.065$ \\
\hline Clonal evolution at diagnosis & 0.031 & 0.028 & 2.841 & $1.121-7.149$ \\
\hline Sokal risk Score & 0.15 & & & \\
\hline Type of TKIs & 0.45 & & & \\
\hline Time from diagnosis to TKI & 0.26 & & & \\
\hline Cumulative response with a time dependent variable & & \\
\hline CCyR & $<0.0001$ & $<0.0001$ & 6.250 & $3.367-11.494$ \\
\hline MMR & $<0.0001$ & $<0.0001$ & 6.579 & $3.745-11.628$ \\
\hline MR4.5 & $<0.0001$ & $<0.0001$ & 5.154 & $2.841-9.346$ \\
\hline CMR & $<0.0001$ & 0.0013 & 3.003 & $1.538-5.882$ \\
\hline
\end{tabular}

* Each variable was compared to the counterpart no response category and calculated for multivariate analysis separately.

Abbreviations: TKI, tyrosine kinase inhibitor; HR, hazard ratio; CI, confidence interval; CCyR, complete cytogenetic response; MMR, major molecular response; MR4.5, molecular response with 4.5 log reduction by international scale; CMR, complete molecular response; OS, overall survival.

\section{Table 5}

One-year landmark by cumulative response within one year

\begin{tabular}{|c|c|c|c|c|c|c|c|c|}
\hline Group & $\begin{array}{l}\text { No. } \\
\text { at } 5 y\end{array}$ & $\begin{array}{c}\text { 5-y Absolute } \\
\text { OS } \\
{\left[\begin{array}{c}\text { [95\% CI] } \\
\end{array}\right.}\end{array}$ & $\begin{array}{c}\text { 5-y Relative OS } \\
{[95 \% \text { CI }]}\end{array}$ & $\begin{array}{l}5-y \text { OS } \\
\text { in GP }\end{array}$ & $\begin{array}{l}\text { No. } \\
\text { at } 10 y\end{array}$ & $\begin{array}{c}\text { 10-y Absolute } \\
\text { OS } \\
{[95 \% \mathrm{CI}]}\end{array}$ & $\begin{array}{c}\text { 10-y Relative OS } \\
{[95 \% \mathrm{CI}]}\end{array}$ & $\begin{array}{l}\text { 10-y OS } \\
\text { in GP }\end{array}$ \\
\hline \multicolumn{9}{|l|}{ Age 15-84 } \\
\hline All N=465 & 312 & $93.5[91 \cdot 0-95 \cdot 9]$ & $95 \cdot 1[92 \cdot 6-97 \cdot 6]$ & $98 \cdot 3$ & 127 & $84 \cdot 2[79 \cdot 9-88 \cdot 6]$ & $88 \cdot 4[83 \cdot 9-93 \cdot 1]$ & $95 \cdot 2$ \\
\hline CCyR N=413 & 284 & $95 \cdot 2[92 \cdot 8-97 \cdot 5]$ & $97 \cdot 0[94 \cdot 6-99 \cdot 4]$ & $98 \cdot 1$ & 115 & $87 \cdot 7[83 \cdot 4-92 \cdot 0]$ & $92 \cdot 3[87 \cdot 8-96 \cdot 8]$ & $95 \cdot 0$ \\
\hline MMR N=338 & 234 & $97 \cdot 3$ [95.4-99.3] & $99 \cdot 1[97 \cdot 1-101 \cdot 1]$ & $98 \cdot 2$ & 91 & $89 \cdot 9$ [85.3-94.4] & $94 \cdot 6$ [89.8-99.4] & $95 \cdot 0$ \\
\hline MR4.5 N=159 & 105 & $95 \cdot 8[92 \cdot 1-99 \cdot 4]$ & $97 \cdot 8[94 \cdot 0-101 \cdot 4]$ & $98 \cdot 0$ & 47 & $88.5[81.9-95 \cdot 0]$ & $93 \cdot 5[86 \cdot 5-100 \cdot 3]$ & $94 \cdot 7$ \\
\hline CMR N=81 & 53 & $98 \cdot 6[95 \cdot 8-100]$ & $100 \cdot 5[97.7-101.9]$ & $98 \cdot 1$ & 21 & $91 \cdot 7[82 \cdot 2-100]$ & $96 \cdot 8[86 \cdot 8-105 \cdot 6]$ & $94 \cdot 7$ \\
\hline \multicolumn{9}{|l|}{ Age 15-44 } \\
\hline All N=189 & 131 & $96 \cdot 2[93 \cdot 2-99 \cdot 2]$ & $96 \cdot 9$ [93.9-99.9] & $99 \cdot 3$ & 48 & $90 \cdot 0[84 \cdot 4-95 \cdot 6]$ & $91.6[85.9-97 \cdot 4]$ & $98 \cdot 2$ \\
\hline CCyR N=160 & 117 & $99 \cdot 2[97 \cdot 7-100]$ & $99.9[98 \cdot 4-100 \cdot 7]$ & $99 \cdot 3$ & 42 & $95 \cdot 5[90 \cdot 9-100]$ & $97 \cdot 3[92 \cdot 6-101 \cdot 8]$ & $98 \cdot 2$ \\
\hline MMR N=131 & 95 & $99 \cdot 1[97 \cdot 2-100]$ & $99 \cdot 8$ [97.9-100.7] & $99 \cdot 3$ & 34 & $96 \cdot 0[91 \cdot 4-100]$ & $97.9[93.2-101 \cdot 9]$ & $98 \cdot 1$ \\
\hline MR4 $5 \mathrm{~N}=60$ & 41 & 100 & $100 \cdot 7$ & $99 \cdot 3$ & 19 & $97 \cdot 0[91 \cdot 1-100]$ & $99 \cdot 0[93 \cdot 0-102 \cdot 0]$ & $98 \cdot 0$ \\
\hline CMR N=32 & 21 & 100 & $100 \cdot 7$ & $99 \cdot 3$ & 10 & 100 & $102 \cdot 1$ & 97.9 \\
\hline \multicolumn{9}{|l|}{ Age 45-64 } \\
\hline All N=214 & 140 & $94 \cdot 4[90 \cdot 9-97 \cdot 8]$ & $97 \cdot 0[93 \cdot 4-100 \cdot 5]$ & $97 \cdot 3$ & 58 & $88 \cdot 0[82 \cdot 4-93 \cdot 6]$ & $94 \cdot 7[88 \cdot 7-100 \cdot 8]$ & $92 \cdot 9$ \\
\hline CCyR N=196 & 130 & $96 \cdot 1[93 \cdot 0-99 \cdot 2]$ & $98 \cdot 8[95 \cdot 6-102 \cdot 0]$ & $97 \cdot 3$ & 54 & $92 \cdot 0[87 \cdot 0-97 \cdot 0]$ & $99 \cdot 0[93 \cdot 6-104 \cdot 4]$ & $92 \cdot 9$ \\
\hline MMR N=164 & 110 & $98 \cdot 5[96 \cdot 5-100]$ & $101 \cdot 2[99 \cdot 2-102 \cdot 8]$ & $97 \cdot 3$ & 43 & $94.6[89.7-99 \cdot 4]$ & $101 \cdot 8[96 \cdot 6-107 \cdot 0]$ & $92 \cdot 9$ \\
\hline MR4. $5 \mathrm{~N}=74$ & 49 & $98 \cdot 2[94 \cdot 8-100]$ & $100 \cdot 7[97 \cdot 2-102 \cdot 6]$ & $97 \cdot 5$ & 20 & $92 \cdot 8[84 \cdot 7-100]$ & $99 \cdot 5[90 \cdot 8-107 \cdot 2]$ & $93 \cdot 3$ \\
\hline
\end{tabular}




\begin{tabular}{|c|c|c|c|c|c|c|c|c|}
\hline Group & $\begin{array}{l}\text { No. } \\
\text { at } 5 y\end{array}$ & $\begin{array}{c}\text { 5-y Absolute } \\
\text { OS } \\
{[95 \% \text { CI] }}\end{array}$ & $\begin{array}{c}\text { 5-y Relative OS } \\
{[95 \% \text { CI }]}\end{array}$ & $\begin{array}{l}5-y \text { OS } \\
\text { in GP }\end{array}$ & $\begin{array}{l}\text { No. } \\
\text { at } 10 y\end{array}$ & $\begin{array}{c}\text { 10-y Absolute } \\
\text { OS } \\
{[95 \% \mathrm{CI}]}\end{array}$ & $\begin{array}{c}\text { 10-y Relative OS } \\
{[95 \% \text { CI }]}\end{array}$ & $\begin{array}{l}\text { 10-y OS } \\
\text { in GP }\end{array}$ \\
\hline CMR N=39 & 24 & 100 & $102 \cdot 8$ & $97 \cdot 3$ & 7 & 100 & $107 \cdot 6$ & $92 \cdot 9$ \\
\hline \multicolumn{9}{|l|}{ Age 65-84 } \\
\hline All N=62 & 41 & $82 \cdot 7[72 \cdot 4-93 \cdot 0]$ & $92 \cdot 4$ [80.9-103.9] & $89 \cdot 5$ & 21 & $60 \cdot 9[46 \cdot 2-75 \cdot 5]$ & $83 \cdot 4[63 \cdot 6-104 \cdot 0]$ & $72 \cdot 6$ \\
\hline CCyR N=57 & 37 & $81 \cdot 3[70 \cdot 2-92 \cdot 3]$ & $90 \cdot 8[78 \cdot 4-103 \cdot 1]$ & 89.5 & 19 & $59.5[44 \cdot 0-74.9]$ & $82 \cdot 0[60 \cdot 6-103 \cdot 2]$ & $72 \cdot 6$ \\
\hline MMR N=43 & 29 & $88 \cdot 3[77 \cdot 5-99 \cdot 1]$ & 99.7 [87.5-111.9] & 88.6 & 14 & $61 \cdot 9[43 \cdot 6-80 \cdot 3]$ & $88 \cdot 9[62 \cdot 6-115 \cdot 4]$ & $69 \cdot 6$ \\
\hline MR4. $5 \mathrm{~N}=25$ & 15 & $80 \cdot 0[62 \cdot 5-97 \cdot 5]$ & $88 \cdot 5[69 \cdot 1-107 \cdot 9]$ & $90 \cdot 4$ & 8 & $61 \cdot 7$ [38.9-94.5] & $82 \cdot 6[52 \cdot 1-126 \cdot 5]$ & $74 \cdot 7$ \\
\hline CMR N=10 & 8 & $88 \cdot 9[68 \cdot 4-100]$ & $98 \cdot 6[75 \cdot 8-110 \cdot 9]$ & $90 \cdot 2$ & 4 & $61 \cdot 0[25 \cdot 6-96 \cdot 3]$ & $82 \cdot 3[34 \cdot 5-130 \cdot 0]$ & $74 \cdot 1$ \\
\hline
\end{tabular}

Abbreviations: OS, overall survival; GP, general population; CI, confidence interval; CCyR, complete cytogenetic response;

MMR, major molecular response; MR4.5, molecular response with 4.5 log reduction by international scale; CMR, complete molecular response.

Table 6

One-year landmark by tyrosine kinase inhibitor and cumulative response within 1 year

\begin{tabular}{|c|c|c|c|c|c|c|c|c|}
\hline Group & $\begin{array}{l}\text { No. } \\
\text { at } 5 y\end{array}$ & $\begin{array}{c}\text { 5-y Absolute } \\
\text { OS } \\
{[95 \% \text { CI] }}\end{array}$ & $\begin{array}{c}\text { 5-y Relative OS } \\
{[95 \% \text { CI] }}\end{array}$ & $\begin{array}{l}5-y \text { OS } \\
\text { in GP }\end{array}$ & $\begin{array}{l}\text { No. } \\
\text { at } 10 y\end{array}$ & $\begin{array}{c}\text { 10-y Absolute } \\
\text { OS } \\
{[95 \% \mathrm{CI}]}\end{array}$ & $\begin{array}{c}\text { 10-y Relative OS } \\
\text { [95\% CI] }\end{array}$ & $\begin{array}{l}\text { 10-y OS } \\
\text { in GP }\end{array}$ \\
\hline \multicolumn{9}{|l|}{ All TKI Group } \\
\hline All N=465 & 312 & $93.5[91 \cdot 0-95 \cdot 9]$ & $95 \cdot 1[92 \cdot 6-97 \cdot 6]$ & $98 \cdot 3$ & 127 & $84 \cdot 2[79 \cdot 9-88 \cdot 6]$ & $88 \cdot 4[83 \cdot 9-93 \cdot 1]$ & $95 \cdot 2$ \\
\hline CCyR N=413 & 284 & $95 \cdot 2[92 \cdot 8-97 \cdot 5]$ & $97 \cdot 0$ [94.6-99.4] & $98 \cdot 1$ & 115 & 87.7 [83.4—92.0] & $92 \cdot 3[87 \cdot 8-96 \cdot 8]$ & $95 \cdot 0$ \\
\hline MMR N=338 & 234 & $97 \cdot 3[95 \cdot 4-99 \cdot 3]$ & $99 \cdot 1[97 \cdot 1-101 \cdot 1]$ & $98 \cdot 2$ & 91 & $89 \cdot 9[85 \cdot 3-94 \cdot 4]$ & $94 \cdot 6[89 \cdot 8-99 \cdot 4]$ & $95 \cdot 0$ \\
\hline MR $4 \cdot 5 \mathrm{~N}=159$ & 105 & $95 \cdot 8[92 \cdot 1-99 \cdot 4]$ & $97.8[94 \cdot 0-101 \cdot 4]$ & $98 \cdot 0$ & 47 & $88.5[81 \cdot 9-95 \cdot 0]$ & $93.5[86 \cdot 5-100 \cdot 3]$ & $94 \cdot 7$ \\
\hline CMR N=81 & 53 & $98 \cdot 6[95 \cdot 8-100]$ & $100 \cdot 5[97 \cdot 7-101 \cdot 9]$ & $98 \cdot 1$ & 21 & $91 \cdot 7[82 \cdot 2-100]$ & $96 \cdot 8[86 \cdot 8-105 \cdot 6]$ & $94 \cdot 7$ \\
\hline \multicolumn{9}{|l|}{ Imatinib Group } \\
\hline All N=266 & 239 & $93 \cdot 1[90 \cdot 0-96 \cdot 2]$ & $94.7[91.6-97.9]$ & $98 \cdot 3$ & 127 & $83.9[79 \cdot 2-88 \cdot 6]$ & $88 \cdot 1[83 \cdot 2-93 \cdot 1]$ & $95 \cdot 2$ \\
\hline CCyR N=228 & 212 & $95 \cdot 1[92 \cdot 3-97 \cdot 9]$ & $96 \cdot 9[94 \cdot 1-99 \cdot 8]$ & $98 \cdot 1$ & 115 & $87 \cdot 8[83 \cdot 2-92 \cdot 3]$ & $92 \cdot 6[87 \cdot 8-97 \cdot 4]$ & $94 \cdot 8$ \\
\hline MMR N=183 & 176 & $97 \cdot 8$ [95.7-99.9] & 99.6 [97.5-101.7] & $98 \cdot 2$ & 91 & $90 \cdot 5[85 \cdot 8-95 \cdot 2]$ & $95 \cdot 3[90 \cdot 3-100 \cdot 2]$ & $95 \cdot 0$ \\
\hline MR4.5 N=81 & 78 & $97 \cdot 5[94 \cdot 1-100]$ & $99 \cdot 6[96 \cdot 1-102 \cdot 5]$ & $97 \cdot 9$ & 47 & $89 \cdot 7[82 \cdot 9-96 \cdot 5]$ & $95 \cdot 2[88 \cdot 0-102 \cdot 4]$ & $94 \cdot 2$ \\
\hline $\mathrm{CMR} N=34$ & 33 & 100 & $102 \cdot 0$ & $98 \cdot 0$ & 21 & $93 \cdot 1[83 \cdot 7-100]$ & $98.5[88 \cdot 6-105 \cdot 8]$ & $94 \cdot 5$ \\
\hline \multicolumn{9}{|l|}{ Dasatinib Group } \\
\hline All N=101 & 40 & $98 \cdot 5[95 \cdot 6-100]$ & $100 \cdot 1[97 \cdot 2-101 \cdot 6]$ & $98 \cdot 4$ & 0 & NA & NA & $95 \cdot 4$ \\
\hline CCyR N=94 & 39 & $98 \cdot 4[95 \cdot 3-100]$ & $100 \cdot 0[96 \cdot 8-101 \cdot 6]$ & $98 \cdot 4$ & 0 & NA & NA & $95 \cdot 4$ \\
\hline MMR N=75 & 30 & 100 & $101 \cdot 9$ & $98 \cdot 1$ & 0 & NA & NA & $94 \cdot 7$ \\
\hline MR4.5 N=37 & 12 & 100 & $101 \cdot 8$ & $98 \cdot 2$ & 0 & NA & NA & $95 \cdot 1$ \\
\hline $\mathrm{CMR} N=26$ & 9 & 100 & $101 \cdot 8$ & $98 \cdot 2$ & 0 & NA & NA & 94.9 \\
\hline \multicolumn{9}{|l|}{ Nilotinib Group } \\
\hline All N=98 & 33 & $88 \cdot 5[79 \cdot 4-97 \cdot 5]$ & $90 \cdot 1$ [80.9-99.3] & $98 \cdot 2$ & 0 & NA & NA & $95 \cdot 0$ \\
\hline CCyR N=91 & 33 & $90 \cdot 7[82 \cdot 0-99 \cdot 5]$ & $92.5[83.6-101 \cdot 4]$ & $98 \cdot 1$ & 0 & NA & NA & $94 \cdot 7$ \\
\hline MMR N=80 & 28 & $92 \cdot 0[83 \cdot 3-100]$ & $93 \cdot 7[84 \cdot 8-101 \cdot 8]$ & $98 \cdot 2$ & 0 & NA & NA & $94 \cdot 8$ \\
\hline MR4.5 N=41 & 15 & $85 \cdot 6[70 \cdot 2-100]$ & $87 \cdot 3[71 \cdot 6-102 \cdot 0]$ & $98 \cdot 0$ & 0 & NA & NA & $94 \cdot 6$ \\
\hline CMR N=21 & 11 & $94 \cdot 1[82 \cdot 9-100]$ & 95.9 [84.5-101.9] & $98 \cdot 1$ & 0 & NA & NA & $94 \cdot 7$ \\
\hline
\end{tabular}


Abbreviations: OS, overall survival; GP, general population; CI, confidence interval; CCyR, complete cytogenetic response; MMR, major molecular response; MR4.5, molecular response with 4.5 log reduction by international scale; CMR, complete molecular response; NA, not applicable.

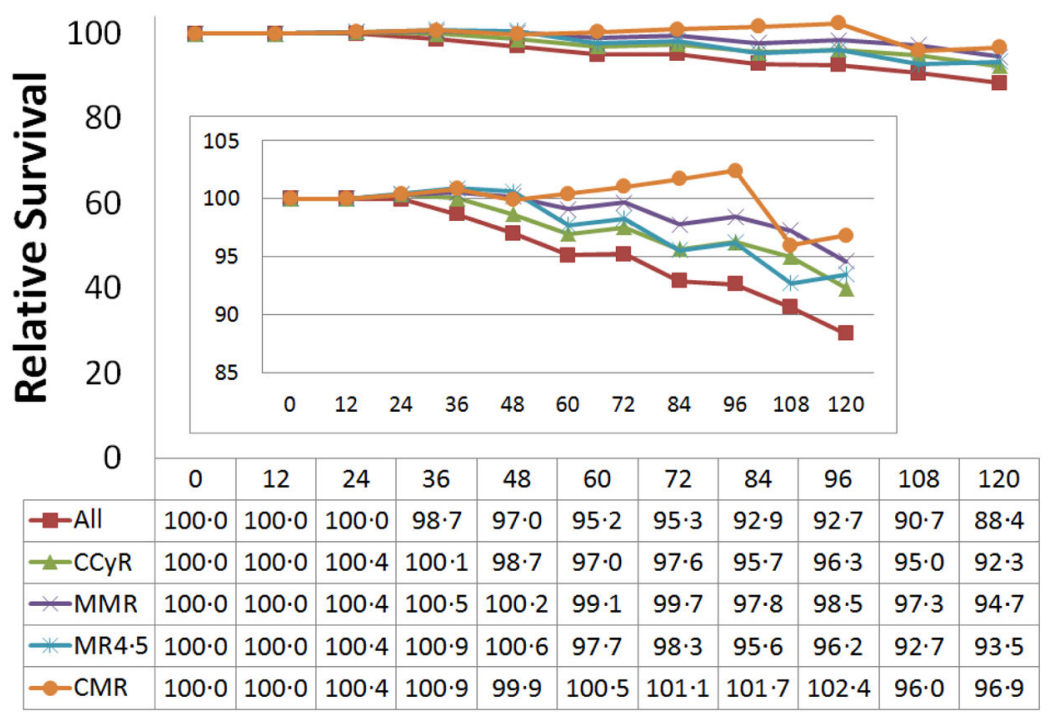

Months

Figure 2-1. One-year landmark: Relative survival in patients with chronic myeloid leukemia by cumulative response within 1 year

Abbreviations: CCyR, complete cytogenetic response; MMR, major molecular response; MR4.5, molecular response by a $4.5 \log$ reduction on the international scale; CMR, complete molecular response. 


\section{Panel: Research in context}

We searched PubMed between January, 2000, and December 2014, with various combinations of the search terms: "chronic myeloid leukemia", "tyrosine kinase inhibitor", "relative survival", "general population", "cytogenetic response", and "molecular response". We identified four population studies; one using the SEER database from the US ${ }^{7}$; one using 11 cancer registries from Germany ${ }^{9}$; one using national CML registry from Sweden ${ }^{32}$; one using Chronic MyEloid LeukemiA (CAMELIA) registry from Slovakia ${ }^{33}$. Of these four studies, the relative survival in patients with $\mathrm{CML}$ was not assessed by type of TKI, or by the level of response to therapy.

\section{Interpretation}

In this prospective analysis in the setting of six consecutive or parallel clinical trials, we report relative survival in patients with newly diagnosed chronic myeloid leukemia in chronic phase compared to general population matched by age, sex, race, and calendar year at diagnosis. Patients treated with tyrosine kinase inhibitor have an overall survival only slightly lower to that of matched general population. In particular, patients who achieved complete cytogenetic response or better within one year of therapy have all excellent survival. The discrepancy between our results and previously published articles suggests lack of access to tyrosine kinase inhibitor might be a significant factor for decreased relative survival in patients with chronic myeloid leukemia in chronic phase. 


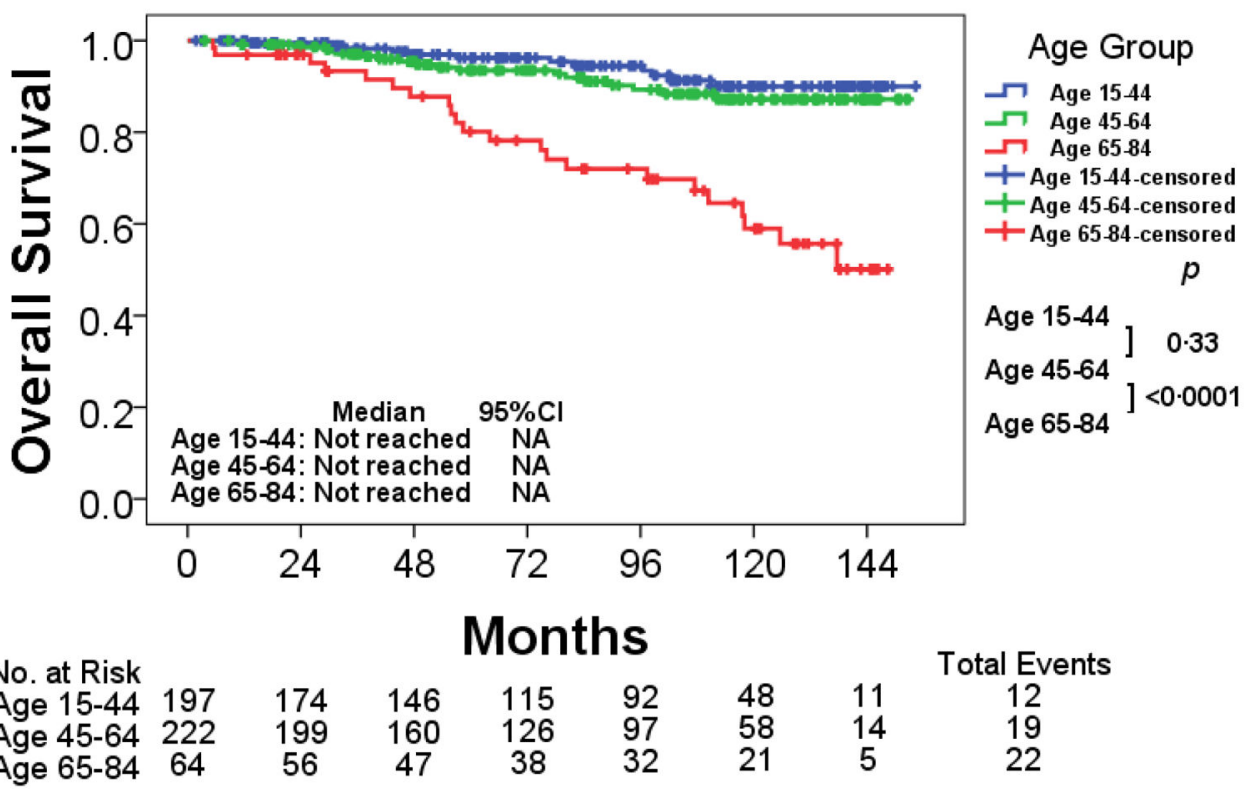

Figure 1. Overall survival by age group

Abbreviations: CI, confidence interval; NA, not applicable. 


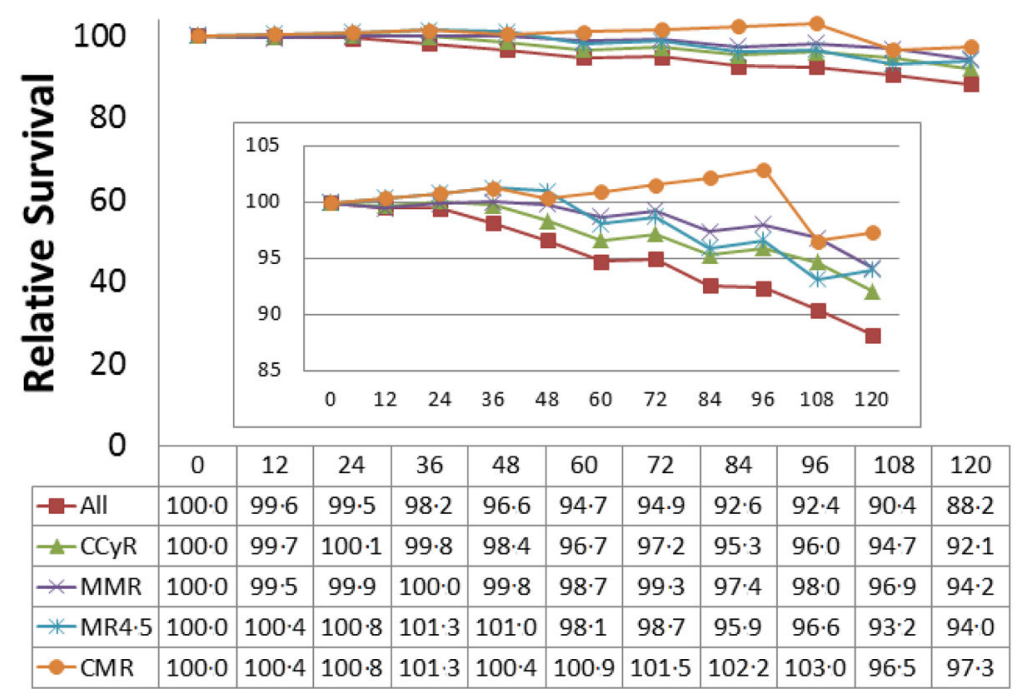

Months

Figure 2. Relative survival in patients with chronic myeloid leukemia by cumulative response within 1 year*

Abbreviations: CCyR, complete cytogenetic response; MMR, major molecular response;

MR4.5, molecular response by a $4.5 \mathrm{log}$ reduction on the international scale; CMR, complete molecular response.

*: The figure was intended to show the comparison of survival in each response group to that of general population in one figure. 
Table 1

Patient characteristics and outcomes by age group

\begin{tabular}{|c|c|c|c|c|}
\hline & \multicolumn{3}{|c|}{ No. $(\%)$ or Median (range) } & \multirow{2}{*}{$P$} \\
\hline & Age 15-44 [n=197] & Age 45-64 [n=222] & Age 65-84 [n=64] & \\
\hline Median age, year (range) & $36(15 \cdot 1-44 \cdot 9)$ & $53(45 \cdot 1-64 \cdot 9)$ & $70(65 \cdot 2-84 \cdot 8)$ & - \\
\hline Male, No. (\%) & $125(63)$ & $124(56)$ & $38(59)$ & $0 \cdot 29$ \\
\hline \multicolumn{5}{|l|}{ Ethnicity, No. (\%) } \\
\hline Caucasian & $153(78)$ & $171(77)$ & $62(97)$ & \multirow{5}{*}{0.028} \\
\hline African-American & $12(6)$ & $16(7)$ & $1(2)$ & \\
\hline Hispanic & $23(12)$ & $24(11)$ & $1(2)$ & \\
\hline Asian & $4(2)$ & $9(4)$ & 0 & \\
\hline Other & $5(3)$ & $2(1)$ & 0 & \\
\hline Median follow-up, months (range) [IQR] & $94(2-154)[47-120]$ & 89 (4-153) [43-122] & $121(5-148)[44-128]$ & 0.87 \\
\hline \multicolumn{5}{|l|}{ Sokal risk score, No. (\%) } \\
\hline Low & $156(79)$ & $161(73)$ & $18(28)$ & \multirow{3}{*}{$<0 \cdot 0001$} \\
\hline Intermediate & $28(14)$ & $49(22)$ & $39(61)$ & \\
\hline High & $13(7)$ & $12(5)$ & $7(11)$ & \\
\hline \multicolumn{5}{|l|}{ Initial TKI, No. (\%) } \\
\hline Imatinib & $113(57)$ & $116(52)$ & $42(66)$ & \multirow{3}{*}{$0 \cdot 32$} \\
\hline Nilotinib & $42(21)$ & $50(23)$ & $13(20)$ & \\
\hline Dasatinib & $42(21)$ & $56(25)$ & $9(14)$ & \\
\hline Clonal evolution at diagnosis, No. (\%) & $7(4)$ & $7(3)$ & $6(9)$ & $0 \cdot 077$ \\
\hline Diagnosis to treatment, day (range) & $26(0-377)$ & $28(1-215)$ & $24(0-122)$ & 0.33 \\
\hline \multicolumn{5}{|c|}{ Cumulative response to TKI within 1 year, No. (\%) } \\
\hline CCyR & $165(84)$ & $202(91)$ & $58(91)$ & $0 \cdot 059$ \\
\hline MMR & $136(69)$ & $169(76)$ & $44(69)$ & $0 \cdot 31$ \\
\hline MR4.5 & $62(31)$ & $75(34)$ & $25(39)$ & 0.56 \\
\hline CMR & $34(17)$ & $40(18)$ & $10(16)$ & $0 \cdot 91$ \\
\hline \multicolumn{5}{|c|}{ Overall cumulative response to TKI, No. (\%) } \\
\hline CCyR & $171(87)$ & $207(93)$ & $59(92)$ & $0 \cdot 077$ \\
\hline MMR & $152(77)$ & $183(82)$ & $52(81)$ & 0.44 \\
\hline MR4.5 & $127(64)$ & $158(71)$ & $47(73)$ & $0 \cdot 24$ \\
\hline CMR & $91(46)$ & $124(56)$ & $33(52)$ & $0 \cdot 16$ \\
\hline 5-year OS, \% (95\% CI) & $96(93 \cdot 2-99 \cdot 2)$ & $94(89 \cdot 9-97 \cdot 1)$ & $80(69 \cdot 5-90 \cdot 7)$ & $<0.0001$ \\
\hline
\end{tabular}

Abbreviations: TKI, tyrosine kinase inhibitor; CCyR, complete cytogenetic response; MMR, major molecular response; MR4·5, molecular response with $4.5 \log$ reduction by international scale; CMR, complete molecular response; OS, overall survival; CI, confidence interval; IQR, interquartile range. 


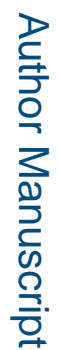

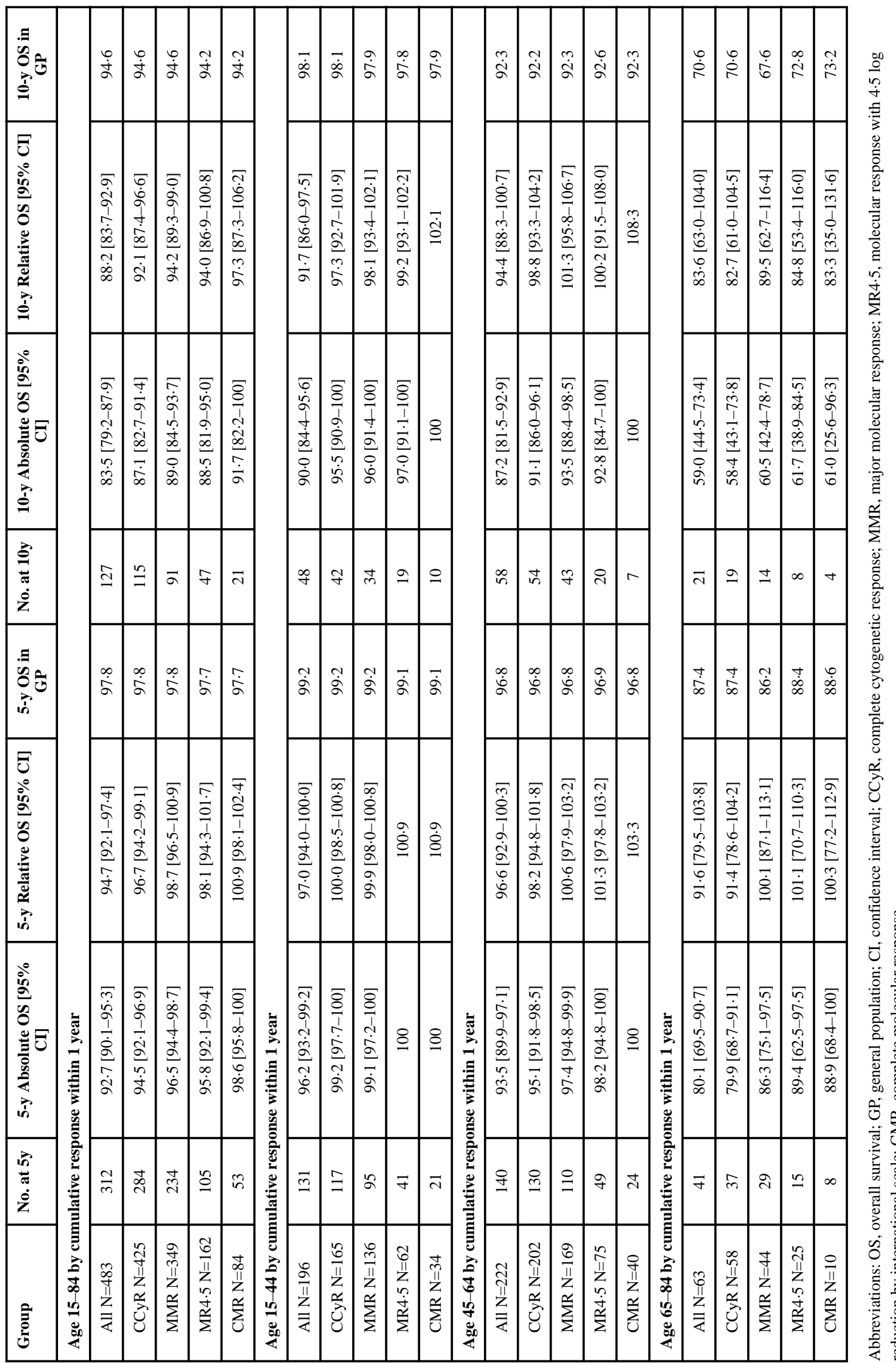

Lancet Haematol. Author manuscript; available in PMC 2016 May 27. 


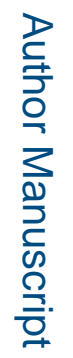

I

敢

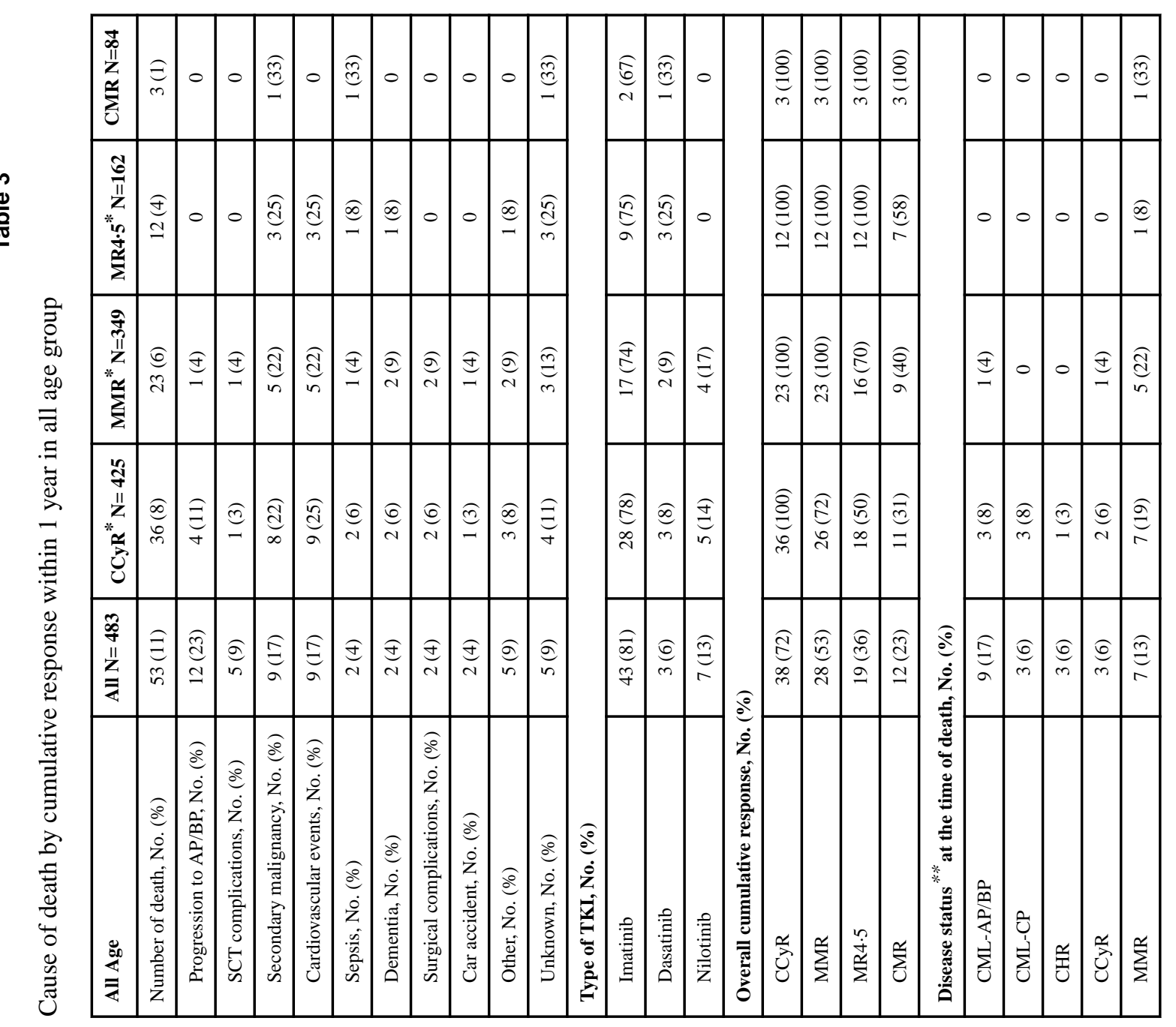

Lancet Haematol. Author manuscript; available in PMC 2016 May 27. 


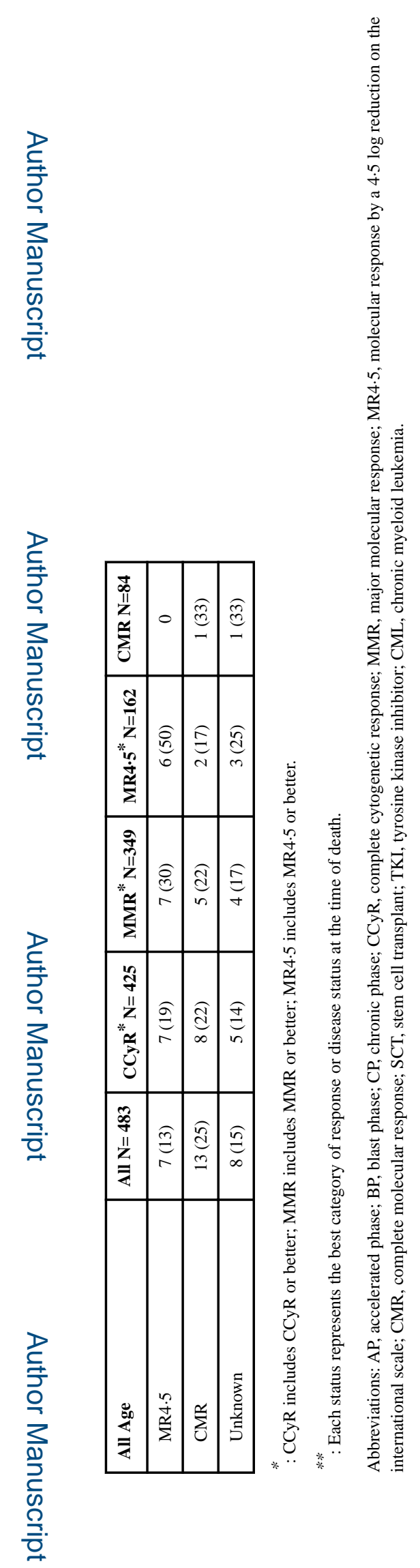

